\title{
Efficacy of repeated 5-fluorouracil needling for failing and failed filtering surgeries based on simple gonioscopic examination
}

This article was published in the following Dove Press journal:

Clinical Ophthalmology

27 December 2012

Number of times this article has been viewed

\section{Mohammad A Rashad \\ Ophthalmology Department, Faculty of Medicine, Ain Shams University, Cairo, Egypt}

Correspondence: Mohammad A Rashad Ali Amen Street, Nasr City, Cairo, Egypt Tel 0 I223463327

Email mahmad_r@yahoo.com
Purpose: To evaluate the success rate of a modified bleb needling technique in eyes with previous glaucoma surgery that had elevated intraocular pressure.

Methods: A retrospective study of 24 eyes of 24 patients that underwent repeated bleb needling performed for failing and failed blebs on slit lamp with 5-fluorouracil (5-FU) injections on demand. This was performed after gonioscopic examination to define levels of filtration block.

Results: There was significant reduction of mean IOP from $36.91 \mathrm{mmHg}$ to $14.73 \mathrm{mmHg}$ at the final follow-up $(P<0.001)$. The overall success rate was $92 \%$.

Conclusion: Repeated needling with adjunctive 5-FU proved a highly effective, safe alternative to revive filtration surgery rather than another medication or surgery.

Keywords: bleb, failure, 5-FU, needling, gonioscopy

\section{Introduction}

Trabeculectomy is still the gold standard surgical procedure for treatment of glaucoma. It entails opening a fistula between the anterior chamber and the subconjunctival space, generating a reservoir for aqueous humor. It has a success rate of $67 \%-94 \% .{ }^{1}$ Early and late failure of filtering bleb due to fibrotic proliferation is especially reported in uveitis, aphakia, neovascular, and recurrent glaucomas. ${ }^{2}$ A second trabeculectomy, especially in the aforementioned cases, may have a similar or lower success rate to the first procedure with the sacrifice of more virgin conjunctiva. ${ }^{1}$ Drainage device implants including new generation ones, such as the Ex-PRESS Mini Glaucoma Shunt (Alcon, Houston, TX), ${ }^{3}$ have a final (36-month) probability success rate of $50.9 \%$ and $60.6 \%$ in eyes with previous trabeculectomy and previous cataract surgery, respectively. ${ }^{4}$ It is, furthermore, a more expensive alternative. ${ }^{3,4}$

Reinstitution of topical treatment may not be enough to control the intraocular pressure (IOP) or may be associated with poor compliance and more conjunctival damage. $^{5}$

Cyclodestructive procedures, including cyclophotocoagulation, have an inherent unpredictability and present a risk of hypotony and visual loss. ${ }^{6}$ Needle revision with 5-fluorouracil (5-FU) was first reported by Ewing and Stamper. ${ }^{7}$ Glaucoma surgery fails because of aqueous blocks at the levels of the internal ostium, intrascleral, or subconjunctival space. ${ }^{1}$ Intrascleral and episcleral fibrosis are responsible for blockages in the last two levels. ${ }^{1}$ Our study utilized a proper algorithm to exclude internal ostium blocks first by gonioscopy. We used gonioscopy to define the level of obstruction of 
aqueous outflow, then assessed needling as a way to eradicate all fibrous tissue present in the episcleral and intrascleral levels. Most studies in the literature have focused on needle revisions performed in the early postoperative periods. ${ }^{8,9}$

We are aiming to assess the efficacy of needling for both early and late bleb failure months and years after the original surgery.

\section{Patients and methods}

The study was retrospective and included 24 eyes of 24 patients operated upon by the same surgeon from December 2009 to December 2011.

\section{Inclusion criteria}

- Impending failure due to flattening and increased vascularization.

- Failed previous glaucoma surgery.

- Patent internal ostium of filtration surgery site.

- Failure to achieve target IOP despite surgery, and/or medical treatment.

In all cases, an informed consent form was provided prior to surgery that explained the use of needling to improve bleb function.

\section{Exclusion criteria}

- Eyes with internal iris block.

- Leaky bleb.

- Corneal epithelial complications.

- Fornix-based conjunctival flap in early postoperative period.

- Eyes with more than one filtering surgery.

The descriptive parameters were age, sex, type of glaucoma, time elapsed since surgery, bleb morphology, IOP, and number of antiglaucoma medications used by the patient. Examination of cup-to-disc (CD) ratio was confirmed by an optical coherence tomography (OCT) assessment of the retinal nerve fiber layer (RNFL) thickness. Field examination with Humphrey field analyzer (Carl Zeiss) or Octopus field analyzer (Haag Streit International, Koeniz, Switzerland) and central corneal thickness (CCT) assessment were performed for all patients.

IOP was measured by Goldmann applanation tonometry on 2 different preoperative days, and the mean value was calculated as a baseline IOP. Gonioscopic examination was done by Goldmann three-mirror contact lens. The gonioscope lens was oriented for a view of ostium of the filtration surgery site. According to internal examination, eyes were classified to episcleral fibrosis (flap elevated from its bed) and intrascleral fibrosis (flap attached to its bed) after exclusion of the eyes with internal block. Bleb was considered failing if it was vascularized with gradually raising IOP (Figure 1). Failed bleb was considered if it was completely flattened with elevated IOP. The needling procedure was performed in-office using a slit lamp for proper visualization of the layers. Topical anesthesia was $0.5 \%$ proparacaine drops and microsponge soaked in $2 \%$ lidocaine applied to the conjunctival surface. Eyelids and surrounding skin were prepared with a $10 \%$ povidone-iodine solution. Lidocaine $2 \% 0.1 \mathrm{~mL}$ was drawn into a 25 -gauge needle insulin syringe. 5 -FU ( $5 \mathrm{mg} / 0.1 \mathrm{~mL})$ standard dose was drawn into another 25-gauge needle insulin syringe.

The needle of the lidocaine syringe was introduced about $10 \mathrm{~mm}$ away from the bleb and away from conjunctival blood vessels. The needle was inserted slowly and gently to reach the bleb. In case of episcleral fibrosis, the needle was moved in a side-to-side motion, breaking episcleral adhesions around the bleb and over the scleral flap. In cases of intrascleral fibrosis, the needle was introduced beneath the flap by moving the needle side-to-side, breaking adhesions and cutting suture, if present. If the patient had some pain, the plunger was pushed slowly to inject subconjunctival lidocaine. If IOP was still high, the procedure was repeated to break more adhesions. The needle of the syringe containing 5-FU was introduced subconjunctivally away from the needling site. Postneedling treatment consisted of a combination of tobramycin and dexamethasone 1\% (TobraDex; Alcon) six times a day for 3 days and ciprofloxacin $0.3 \%$ every 2 hours on the first day and 6 times a day for 2 days thereafter. The patient was examined 2-3 days later.

Subconjunctival injection of $5 \mathrm{mg}$ in $0.1 \mathrm{~mL} 5-\mathrm{FU}$ near the bleb was repeated every visit for a minimum of five injections. Repetition of 5-FU injections was

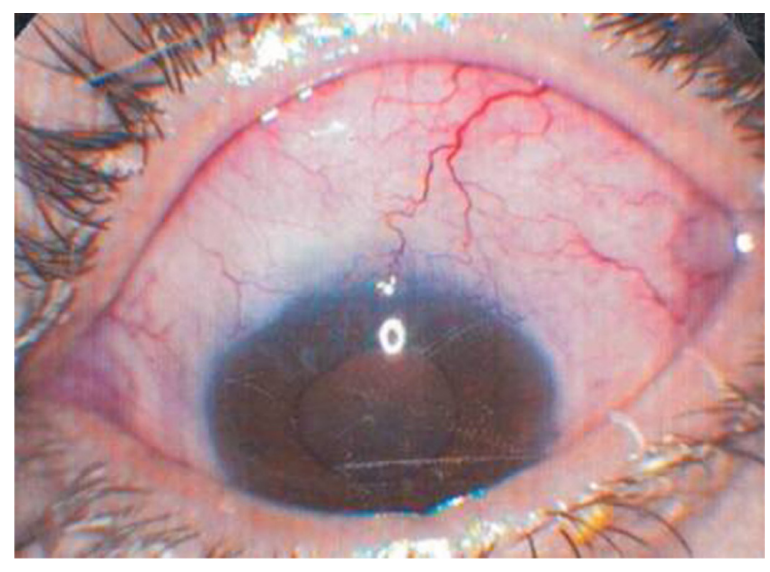

Figure I Flat vascularized failing bleb of eye 5 before needling. 
stopped when large blood vessels above and near the bleb disappeared (Figure 2). It was also stopped if any epithelial defect or complication appeared. IOP was measured every visit. If IOP was elevated beyond the target IOP, needling was repeated. We performed needling when necessary, to a maximum of three times. Every needling procedure was associated with 5-FU injection. If IOP was still elevated after the third needling, medical treatment was reinstituted. Postneedling visits were scheduled every other day or twice a week, depending on IOP elevation. The minimum interval of 5-FU injections with or without needling repetition was 48 hours.

Target IOP was identified according to glaucoma severity. Based on the Early Manifest Glaucoma Trial (EMGT), ${ }^{10,11}$ glaucoma was considered moderate when eyes had a vertical $\mathrm{CD}$ ratio of 0.7 to 0.85 , or when they had one hemifield defect with mean deviation (MD) from -6 to -12 , not within $10^{\circ}$ of fixation, or both. In these eyes, the target IOP was set at $<17 \mathrm{mmHg}$ with a reduction of at least $30 \%$ from the baseline IOP. Eyes were classified as having advanced disease, based on the Advanced Glaucoma Intervention Study (AGIS), ${ }^{11,12}$ when the vertical CD ratio was 0.9 or greater; the visual field had both hemifields affected; there was a defect encroaching on the central $10^{\circ}$; MD was worse than -12 ; or any of these features occurred together. In these eyes, the target IOP was set at $<14 \mathrm{mmHg}$ with a reduction of at least $30 \%$ from the baseline IOP. The target IOP was corrected accordingly for extreme CCT changes from the assumed $520 \mu \mathrm{m}$ level. ${ }^{13}$

A complete success was defined by achievement of the target IOP without medications. A qualified success was defined by achievement of the target IOP with the aid of hypotensive medication(s). Failure was defined by IOP greater than the target IOP, despite the maximum medications

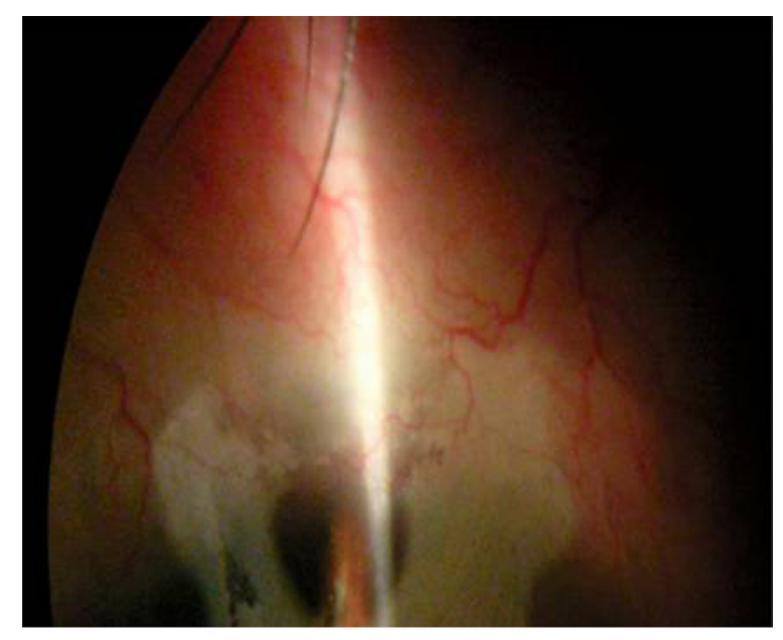

Figure 2 Less-vascularized failing, elevated bleb after first needling and 5-FU injection. (topical medications three entititeis of antiglaucoma in two bottles) used and three needlings having been done.

\section{Statistical methods}

Data were presented as mean and standard deviation (SD) values. Paired sample $t$-test was used to compare two paired groups and independent sample $t$-test was used to compare two independent groups. Spearman's correlation coefficient was used to determine the significant correlations between the studied parameters.

The significance level was set at $P \leq 0.05$. Statistical analysis was performed with statistical package for social science (SPSS) version 16.0 for Windows (IBM Corporation, Armonk, NY).

\section{Results}

Our study included 24 eyes of 24 patients. Age of patients ranged from 29 to 75 years (mean $48.42 \pm 14.36$ years) and included 12 males and 12 females. All patients were from Egypt with the exception of dark race that has a high incidence of filtration surgery failure. Eyes with advanced disease number was 18/24 (66.7\%) (Figures 3-6) and eyes with moderate disease number was 6/24 (33.3\%). None of the eyes had early disease.

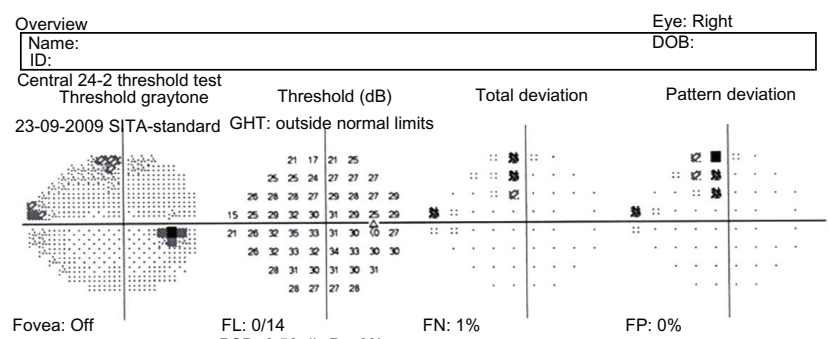
$\begin{array}{llll}\text { Fovea: Off } & \text { FL: } 0 / 14 & \text { FN: } 1 \% & \text { FP: } 0 \% \\ \text { MD: }-1.37 \mathrm{db} & \text { PSD: } 2.52 \mathrm{db} P<2 \% & & \end{array}$

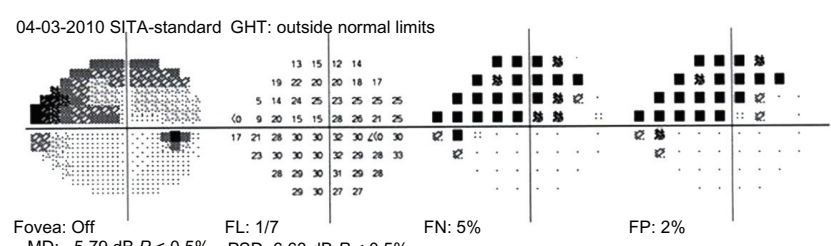
$\begin{array}{llll}\text { Fovea: Off } & \text { FL: } 1 / 7 & \text { FN: } 5 \% & \text { FP: } 2 \% \\ \text { MD: }-5.79 \mathrm{~dB} P<0.5 \% & \text { PSD: } 6.63 \mathrm{~dB} P<0.5 \% & \end{array}$

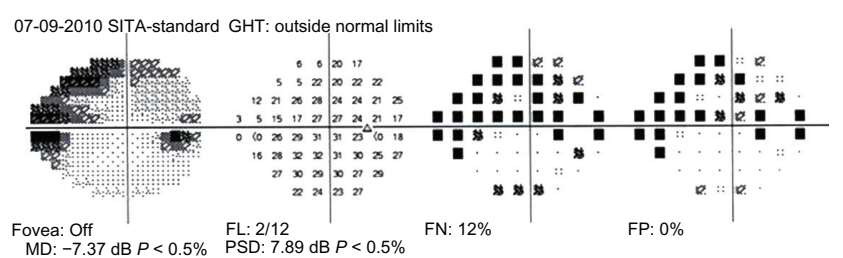

$\begin{array}{ll}\text { Fovea: } & \text { Off } \\ \text { MD: }-7.37 \mathrm{~dB} P<0.5 \% & \text { PSD: } 7.89 \mathrm{~dB} P<0.5 \%\end{array}$

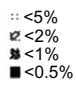

Figure 3 Preoperative serial field examination of eye I with advanced disease. 


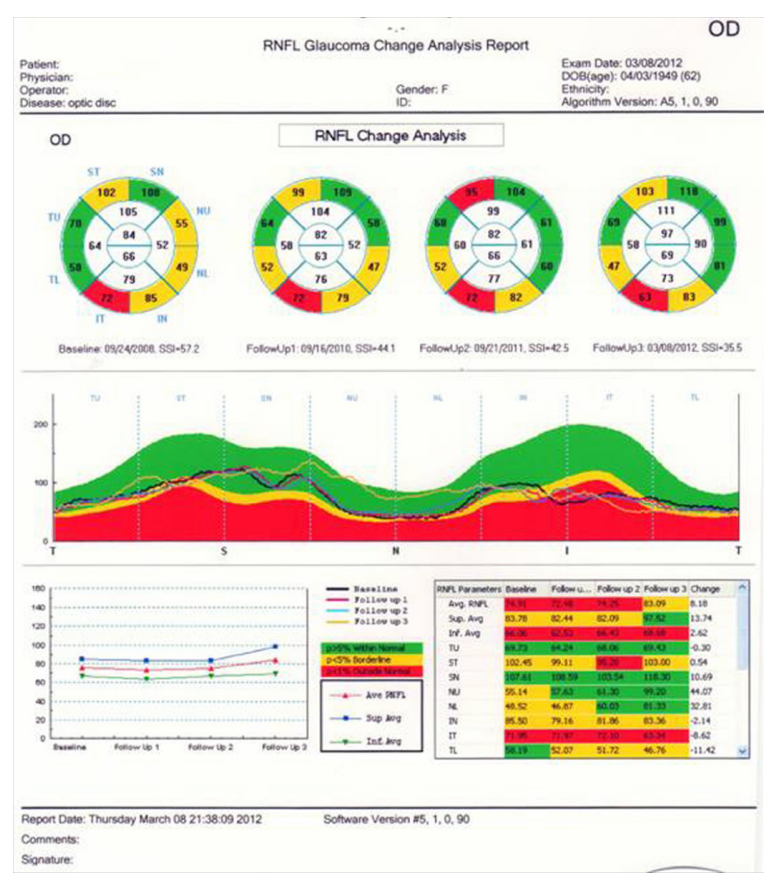

Figure 4 Preoperative serial optical coherence tomography examination of eye I with advanced disease.

The preneedling IOP ranged from 26 to $60 \mathrm{mmHg}$ (mean $36.91 \pm 11.14 \mathrm{mmHg}$ ). Primary open-angle glaucoma was present in eight eyes (33.3\%), pseudophakic glaucoma in eight eyes (33.3\%), uveitic glaucoma in four eyes $(16.7 \%)$, silicone-induced glaucoma in two eyes $(8.3 \%)$, and chronic angle-closure glaucoma in two eyes $(8.3 \%)$.
Eighteen eyes (75\%) were described as having failing blebs and six eyes (25\%) had failed blebs. All eyes had subscleral trabeculectomy. According to gonioscope examination, 18 eyes (75\%) had episcleral fibrosis and six eyes $(25 \%)$ had intrascleral fibrosis.

We performed needling procedures at a mean of 1.83 needlings per eye (SD 0.72). Eight eyes (33\%) were needled once, 12 eyes (50\%) twice, and four eyes (17\%) three times.

Table 1 describes statistical details of needling and 5-FU injections.

The average follow-up after the first needling was 18.2 months (SD 6.0, range 2-50 months). The mean postneedling IOP was $14.73 \pm 5.12 \mathrm{SD}$, which was significantly different from the preoperative IOP. Table 2 describes preneedling and postneedling IOP and medications.

No significant difference was found between postoperative IOP in both the failing and failed groups (Table 3). There was also no significant difference between postoperative IOP reduction and type of block in either the episcleral or intrascleral groups (Table 3).

There was no correlation between number of needling procedures performed and postoperative IOP reduction, and no correlation between the number of 5-FU injections and postoperative IOP reduction (Table 4).

In this study, the overall success rate of needling procedures was $92 \%$. The median survival time for patients was 22 days (Figure 7).
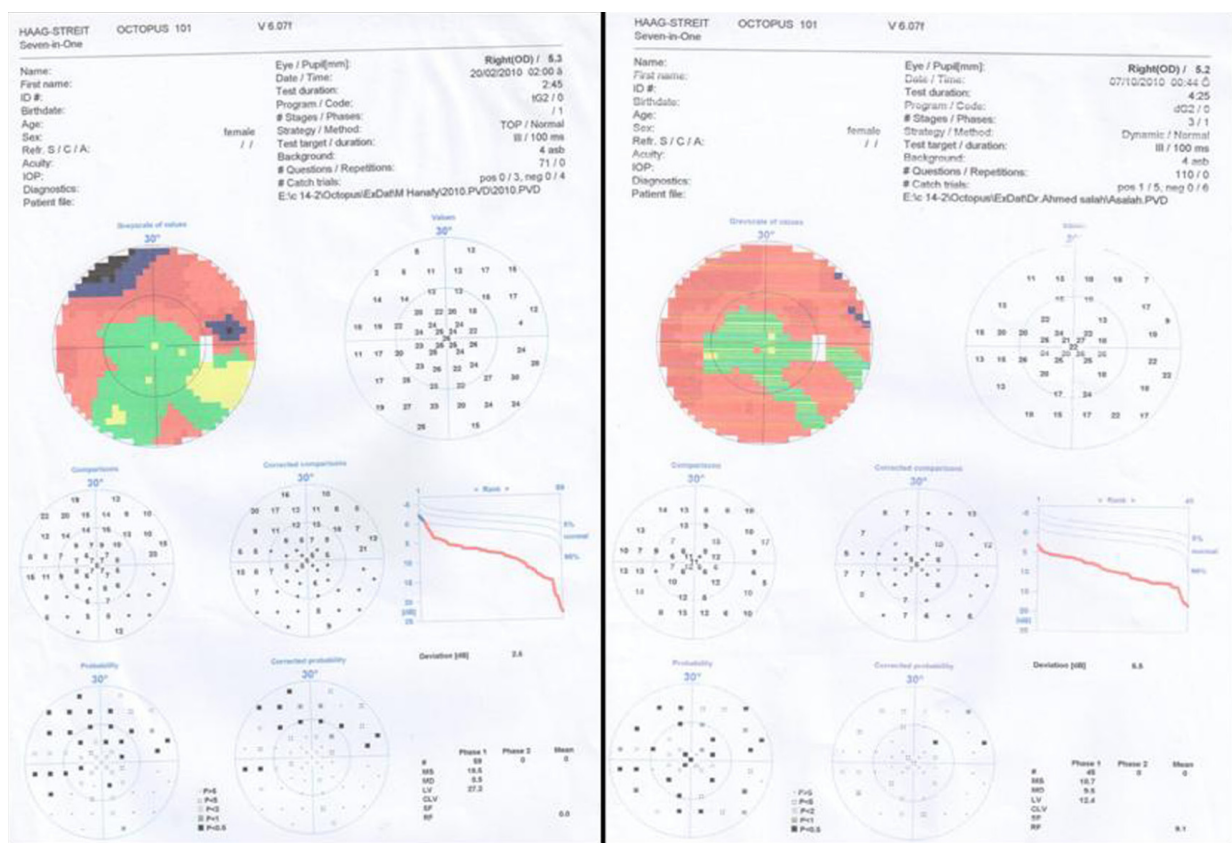

Figure 5 Two successive preoperative field examinations of eye 4 with advanced disease. 


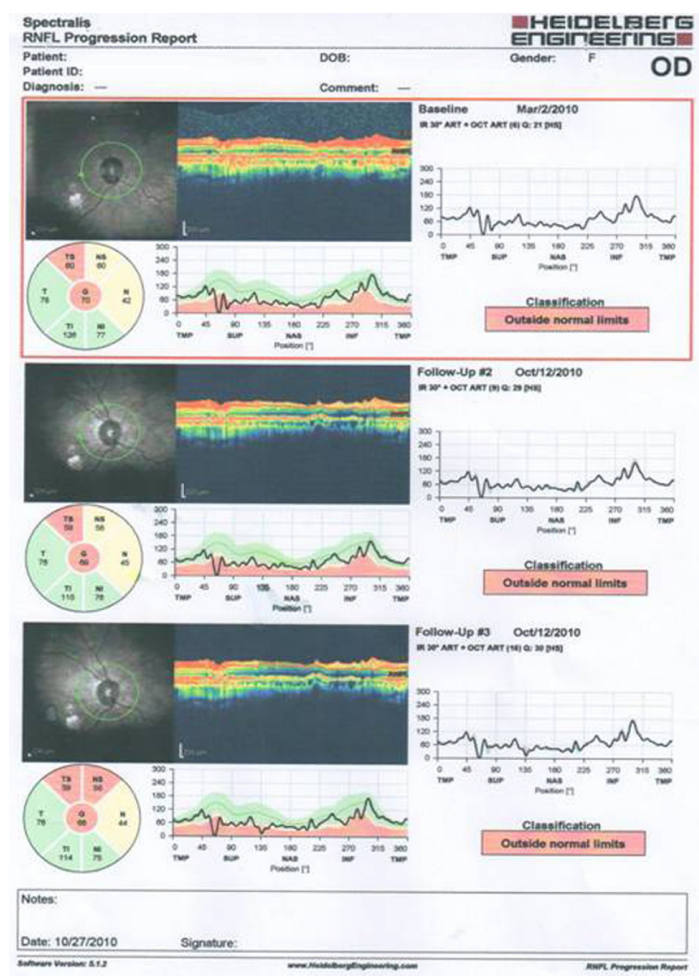

Figure 6 Two preoperative serial optical coherence tomography examinations for retinal nerve fiber layer progression of eye 4 .

Complete success was achieved in 16 eyes (66.7\%); qualified success was achieved in six eyes $(25 \%)$. Needling failure occurred in two eyes (8.3\%). One eye (4.2\%) developed corneal decompensation and two eyes $(8.4 \%)$ had a conjunctival gaped wound that necessitated suturing of the conjunctiva by 7.0 Vicryl sutures (Alcon) for fear of infection. Two eyes $(8.3 \%)$ developed punctuate epithelial erosion that necessitated discontinuation of 5-FU injections and prescription of preservative-free artificial tears (Refresh Plus ${ }^{\circledR}$ eye drops; Allergan Inc, Irvine, CA) every 2 hours until resolution within 1 week. None of the eyes had persistent epithelial defect.

Two eyes (8.4\%) had IOP less than $10 \mathrm{mmHg}$. These eyes underwent a dilated fundus examination due to the possibility of choroidal detachment: only one eye $(4.2 \%)$ had a small peripheral choroidal detachment that resolved

Table I Descriptive statistics of needling and 5-fluorouracil (5-FU) injection

\begin{tabular}{lllll}
\hline Variables & Minimum & Maximum & Mean & SD \\
\hline $\begin{array}{l}\text { Time between filtration } \\
\text { surgery and needling }\end{array}$ & & & & \\
$\begin{array}{l}\text { Failing blebs (weeks) } \\
\text { Failed blebs (years) }\end{array}$ & 3 & 12 & 7.5 & 3.38 \\
Needlings per eye (n) & $\mathrm{I}$ & 8 & 3.5 & 3.1 \\
5-FU injections per eye (n) & 2 & 3 & 1.83 & 0.72 \\
$\begin{array}{l}\text { Interval between 5-FU } \\
\text { injections } \pm \text { needling (days) }\end{array}$ & 2 & 6 & 4.25 & 1.36 \\
\hline
\end{tabular}

Table 2 Comparison between preneedling and postneedling intraocular pressure (IOP) and medications

\begin{tabular}{lllll}
\hline IOP $(\mathbf{m m H g})$ & Mean & SD & $\boldsymbol{t}$ & $\boldsymbol{P}$-value \\
\hline Preneedling & 36.91 & 11.14 & 5.543 & 0.000 \\
Postneedling & 14.73 & 5.12 & & \\
Preneedling medications & 2.28 & 1.11 & -2.875 & 0.028 \\
Postneedling medications & 0.28 & 0.48 & & \\
\hline
\end{tabular}

Notes: $t=$ paired $t$-test; $P<0.05$ was significant; $P<0.001$ highly significant.

spontaneously over 1 week. None of our eyes had postneedling shallow anterior chamber, even those with a gaped conjunctival wound.

\section{Discussion}

Failed filtration surgery is a common and challenging problem. Most failures are caused by fibrous tissue proliferation, which is a natural feature of wound healing. ${ }^{1}$ Needling to break fibrous tissue without the use of antimetabolites has shown a success rate of $7 \%$ and a qualified success rate of $57 \%$, which did not show significant difference from medical treatment alone. ${ }^{14}$ Probability of success of filtering surgery with no intraoperative or postoperative antifibrotic agent was $56 \% .^{15}$ Failing blebs with a fornix-based conjunctival flap in the early postoperative period were excluded from our study to avoid suture dehiscence.

We performed needling using a slit lamp for better visualization of the subconjunctival space, identification of scleral flap, and immediate measure of IOP after needling. This allows further introduction of the needle to subconjunctival space to break adhesions if IOP is still high. Martinez et al also used slit lamp for needling. ${ }^{16}$ Gonioscopy allowed internal examination of the ostium for classification of outflow obstruction into episcleral (subconjunctival) fibrosis and intrascleral fibrosis, which allows for identification of the level to which the needle must be introduced.

We described a significant reduction of mean IOP from $36.91 \mathrm{mmHg}$ to $14.73 \mathrm{mmHg}$ in 18.2 months' follow-up. Durak et $\mathrm{a}^{17}$ described a reduction of mean IOP from $27.8 \mathrm{mmHg}$ to $20.5 \mathrm{mmHg}$.

Table 3 Comparison between postoperative IOP of failing versus failed groups, and episcleral fibrosis versus intrascleral fibrosis groups

\begin{tabular}{llllll}
\hline \multicolumn{2}{l}{ Postneedling IOP (mmH) } & & & \multicolumn{2}{l}{$\begin{array}{l}\text { Independent } \\
\text { t-test }\end{array}$} \\
\cline { 1 - 2 } \cline { 5 - 6 } Groups & Mean & SD & & & $\boldsymbol{t}$ \\
\hline Failing & 14.00 & 5.10 & & 0.363 & 0.724 \\
Failed & 12.50 & 9.54 & & \\
Episcleral fibrosis & 15.0 & 5.63 & & 1.46 & 0.175 \\
Intrascleral fibrosis & 9.0 & 7.94 & & \\
\hline
\end{tabular}

Note: $P>0.05$ not significant. 
Table 4 Correlation between postneedling IOP and number of needlings and injections

\begin{tabular}{lll}
\hline & Post IOP & \\
\cline { 2 - 3 } & $\boldsymbol{r}$ & $\boldsymbol{P}$ \\
\hline Needling procedures (n) & -0.078 & 0.809 \\
5-FU injections (n) & -0.057 & 0.861 \\
\hline
\end{tabular}

Notes: $r=$ Pearson's correlation coefficient; $P>0.05$ not significant.

Our greater reduction of IOP after needling may be related to a greater number of 5-FU injections (4.25/eye) than in Durak et al, who described a mean of 2.45 -FU injections per eye. ${ }^{17}$

Martinez et al $^{16}$ described a reduction of IOP from $26 \mathrm{mmHg}$ to $16.3 \mathrm{mmHg}$ (a $9.5 \mathrm{mmHg}$ reduction). We described a greater reduction of $22 \mathrm{mmHg}$. Also, we described higher overall (complete and qualified) success (92\%) than Martinez et al, who described an overall success rate of $70 \% .{ }^{16}$ The lower success rate of Martinez et al ${ }^{16}$ may be because of a simpler technique that did not break all fibrous adhesions. Martinez et al described repeated subconjunctival punctures for the filtering bleb, whereas our study described side-to-side movement of the needle to remove fibrous adhesions, according to its level as identified by gonioscopy. ${ }^{16}$

Our overall higher success rate can be explained by the breaking of the episcleral as well as intrascleral fibrosis. Furthermore, we used the needle to cut the scleral flap suture if the IOP was not lowered with needling. This explanation can be supported by the results of Mastropasqua et al's postoperative 5-FU use after ocular massage during the first 3 months, in which a cumulative success rate of $100 \%$ was reported. ${ }^{15}$ This may be because of the breaking of intrascleral, early-

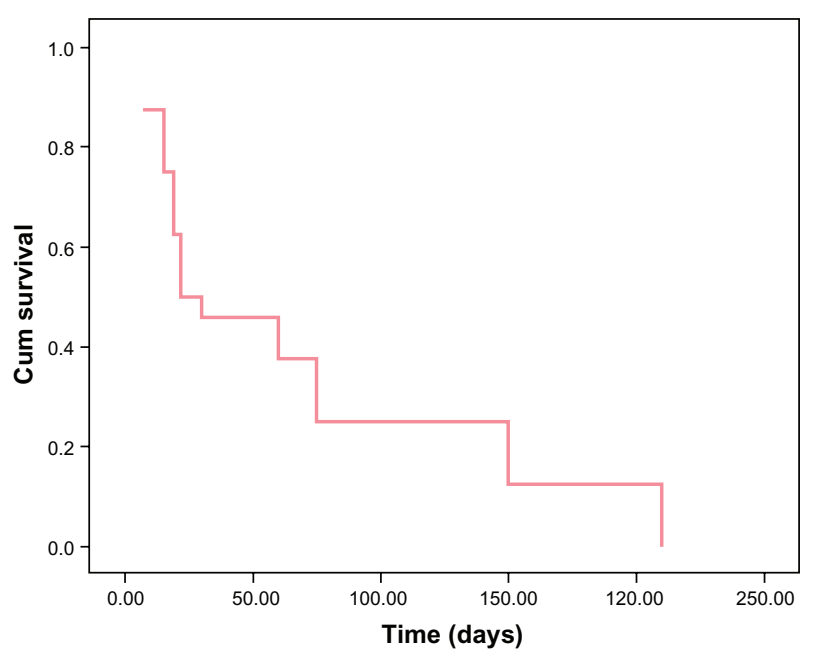

Figure 7 Kaplan-Meier curve of time to achieve target IOP. forming fibrinous proliferations by ocular massage and prevention of reformation by 5-FU injections.

Another study ${ }^{18}$ described a $65 \%$ overall needling success rate 1 year or more after failed trabeculectomy. This could be explained by the single needling procedure performed.

Our success rate also was higher than that of the needling of failed bleb by Maestrini et al, ${ }^{19}$ who reported reestablished aqueous flow with raised bleb immediately in $92 \%$ of their eyes. However, they described only $76 \%$ of their eyes achieving overall IOP less than $16 \mathrm{mmHg}$, including $58 \%$ without medical treatment and $17 \%$ with medical treatment. This may be explained by the technique they used: "We never introduced the needle under the scleral flap or into the anterior chamber." ${ }^{18}$ This means an inability to break intrascleral adhesions.

Maestrini et al used mitomycin C (MMC) as antiproliferative, hence their caution regarding its toxic effect on corneal endothelium with anterior chamber entry. ${ }^{19} \mathrm{We}$ used 5-FU, even though MMC seems to be more effective for needle revisions in terms of the number of injections. ${ }^{20}$ We described 5-FU injection away from the needling site and using a different needle from that used for needling. We also injected 5-FU slowly, monitoring both subconjunctival space and anterior chamber on the slit lamp. We found that 5-FU allows for more gradual modulation of the healing response by varying the number of postoperative injections. ${ }^{15}$

In a study using needling with $\mathrm{MMC},{ }^{16}$ eleven eyes (8\%) developed hypotony and one of them needed surgical treatment with scleral patch graft. None of our eyes had hypotony less than $5 \mathrm{mmHg}$ and none had significant choroidal detachment, indicating a gradual decrease of IOP with repeated 5-FU injections rather than sudden IOP reduction with $\mathrm{MMC}$. The potency of MMC was indicated by Anand and Khan, ${ }^{20}$ who reported single-needle revision in $47 \%$ of a $5-\mathrm{FU}$ group compared to $80 \%$ of an MMC group $(P=0.009)$. Furthermore, our technique allowed us to break intrascleral fibrous adhesions without fear of endothelial toxicity from 5FU. We used a separate syringe for needling and another one to inject 5-FU away from the bleb site to avoid its leakage inside the eye.

Reviving success of $92 \%$ of the needling procedure represents retrieval of optic nerve in eyes with failed or failing filtering surgery. Another study ${ }^{21}$ reported $80 \%$ success of 5-FU injection in encapsulated bleb after drainage device surgery. This may be because they used needling together with 5 -FU in only $50 \%$ of these eyes. It should be noted, however, that it is difficult to compare studies because of 
differences in inclusion criteria, success criteria, procedures, techniques, and periods of follow-up.

We have noticed that a needling technique with adjuvant 5 -FU injection on demand was equally effective in IOP reduction in both failing bleb and failed bleb, regardless of the time elapsed after trabeculectomy. This is probably because we repeated needling to break already formed fibrous adhesions and repeated 5-FU injections to prevent new fibroblast activity.

Early successful needle revision has been described by other authors. ${ }^{8,9}$ Late needling with MMC was described by Masterini et al, ${ }^{19}$ who described needle revision after 6 months to 30 years for failed trabeculectomy. We have described needling with 5 -FU in $25 \%$ of our eyes from 1 to 10 years after filtering surgery. We also noticed similar IOP reduction in both episcleral and intrascleral levels of fibrous adhesions.

Skuta and Parrish ${ }^{1}$ have described that bleb failure most often results from fibroblast proliferation and subconjunctival fibrosis. To the contrary, Jinza et al ${ }^{22}$ used ultrasound biomicroscopy to study filtering blebs and aqueous drainage routes beneath the scleral flap. They concluded that excessive healing of scleral wounds beneath the scleral flap may be involved in reduced aqueous filtration as well as subconjunctival fibrosis of the filtering bleb. This conclusion supports our modified needling technique to introduce the needle beneath the scleral flap based on gonioscopy result. Jinza et al also stated that an aqueous drainage route beneath the trabeculectomy scleral flap cannot be evaluated by conventional slit-lamp examination. ${ }^{22}$ Another study, by Kaushik et al, ${ }^{23}$ classified bleb failure after trabeculectomy into scleral route patent (SRP) and scleral route occluded (SRO), whereas we used gonioscopy for internal examination of the bleb bed to properly locate sites of fibrosis.

The abovementioned study, ${ }^{23}$ although based on ultrasound biomicroscopy, used sub-Tenon needling in both SRP and SRO eyes. In our study, although based on simpler gonioscopy examination, we introduced the needle beneath the scleral flap in SRO eyes; this explains the failure of all SRO blebs reported by Kaushik et al and our equal outcome in eyes with intrascleral and episcleral fibrosis.

We also found that number of needlings and number of 5-FU injections did not correlate with IOP reduction. This is explained by the fact that we repeated needling as long as fibrous tissue was present and IOP was high. We also repeat 5-FU injections whenever vascularization was detected. These numbers were customized for each eye until target IOP was achieved.
The key study of postoperative use of 5-FU injection ${ }^{24}$ described a 21-injection protocol; however, this regimen is onerous for both patient and physician. We described fewer injections because of our modified needling technique and 5-FU injection beside the bleb. The Fluorouracil Filtering Surgery Study Group ${ }^{24}$ injected 5-FU $180^{\circ}$ away from the bleb, usually in the inferior fornix.

In our study, conjunctival gaping that needed suturing was found in two eyes (8.4\%). In a study using MMC with needling, accidental conjunctival perforation occurred in three eyes, but healed spontaneously within a few days, ${ }^{16}$ and conjunctival hemorrhage was reported in $100 \%$ of needling procedures. We observed that subconjunctival blood was one of the features of successful needling. Other criteria of successful needling were sound or sensation of adhesion release and free movement of the needle in the subconjunctival space. These criteria were usually associated with bleb elevation and reduction of IOP after needling.

Punctate epithelial erosion (PEE) was described in two eyes (8.4\%); Durak et $\mathrm{al}^{17}$ described PEE in up to $44 \%$. Another study ${ }^{25}$ reported $50 \%$ transient corneal epithelial defects. Our lower incidence may be related to meticulous injection only in the subconjunctival space.

One of our patient's eyes (4\%) had corneal endothelial decompensation, probably due to endothelial toxicity. Mazey et al described reversible corneal edema due to endothelial damage. ${ }^{26}$ However, the potential for more serious complications, such as kissing choroidal detachment, ${ }^{27}$ suprachoroidal hemorrhage,${ }^{8}$ malignant glaucoma, ${ }^{19}$ and enodophthalmitis, ${ }^{8}$ should not be overlooked.

The present study had some limitations, namely in being a retrospective study, having a relatively small sample, and inclusion of different glaucoma mechanisms and types.

\section{Conclusion}

Modified needling technique that addresses all fibrous adhesions and even sutures of the flap together with subconjuctival 5-FU injections near the bleb represent a relatively simple and successful technique. Needling is a safe technique that should be considered at any time after filtering surgery to regain bleb function prior to deciding another surgery and even prior to prescribing further medications. Simple gonioscopy helps establish the proper approach to use needling only in cases of open internal ostium. Gonioscoby also helps to define the level in which needling should be performed according to level of block. 


\section{Disclosure}

The author reports no conflict of interest in this work.

\section{References}

1. Skuta GL, Parrish RK 2nd. Wound healing in glaucoma filtering surgery. Surv Opthalmol. 1987;32:149-170.

2. Ruderman JM. Revising the failing filtration bleb. Techniques in Ophthalmology. 2005;3:133-137.

3. Sarkisian SR. Use of injector for Ex-PRESS mini glaucoma shunt. Ophthalmic Surg Lasers Imaging. 2007;38:434-436.

4. Lankaranian D, Razeghinejad MR, Prasad A, et al. Intermediate term results of Ex-Press miniature glaucoma implant under a scleral flap in previously operated eyes. Clin Experiment Ophthalmol. 2011;39(58): 381-382.

5. Kass MA, Gordon M, Meltzer DW. Compliance with topical timolol treatment. Am J Opthalmol. 1987;103:188-193.

6. Kosoko O, Gaasterland DE, Pollack IP, Enger CL. Long-term outcome of initial ciliary ablation with contact diode laser transscleral cyclophotocoagulation for severe glaucoma. The Diode Laser Ciliary Ablation Study Group. Ophthalmology. 1996;103(8):1294-1302.

7. Ewing RH, Stamper RL. Needle revision with and without 5 -fluorouracil for the treatment of failed filtering blebs. Am J Opthalmol. 1990;110: 254-259.

8. Greenfield DS, Miller MP, Suner IJ, Palmberg PF. Needle elevation of the scleral flap for failing filtration blebs after trabeculectomy with mitomycin C. Am J Opthalmol. 1996;122:195-204.

9. Rotchford AP, King JA. Needling revision of trabeculectomies bleb morphology and long-term survival. Ophthalmology. 2008;115: $1148-1153$.

10. Heij LA, Leske MC, Bengtsson B, Hussein M; Early Manifest Glaucoma Trial Group. Reproduction of intraocular pressure and glaucoma progression: results from the Early Manifest Glaucoma Trial. Arch Ophthalmol. 2002;120(10):1286-1279.

11. Canadian Ophthalmological Society Glaucoma Clinical Practice Guideline Expert Committee, Canadian Ophthalmological Society. Canadian Ophthalmological Society evidence-based clinical practice guidelines for the management of glaucoma in the adult eye. Can $J$ Opthalmol. 2009;44 Suppl 1:S7-S93. English and French.

12. [No authors listed]. The Advanced Glaucoma Intervention Study (AGIS): 7. The relationship between control of intraocular pressure and visual field deterioration. The AGIS Investigators. Am J Ophthalmol. 2000;130(4):429-440.

13. Ehlers N, Bramsen T, Sperling S. Applanation tonometry and central corneal thickness. Acta Ophthalmol (Copenh). 1975;53(1):34-43.

14. Costa VP, Correa MM, Kara-Jose N. Needling versus medical treatment in encapsulated blebs. A randomized, prospective study. Opthalmology. 1997;104(8):1215-1220.
15. Mastropasqua L, Carpineto P, Ciancaglini M, Zuppardi E, Lobefalo L, Gallenga PE. Delayed post-operative use of 5-fluorouracil as an adjunct in medically uncontrolled open angle glaucoma. Eye (Lond). 1998; 12(4):701-706.

16. Perucho-Martínez S, Gutiérrez-Díaz E, Montero-Rodríguez M, Mencía-Gutiérrez E, Lago-Llinás MD. Needle revision of late failing filtering blebs after glaucoma surgery. Arch Soc Esp Oftalmol. 2006;81: 517-522. Spanish.

17. Durak I, Ozbek Z, Yaman A, Soylev M, Cingil G. The role of needle revision and 5-fluorouracil application over the filtration site in the management of bleb failure after trabeculectomy: a prospective study. Doc Opthalmol. 2003;106(2):189-193.

18. Kapasi MS, Birt CM. The efficacy of 5-fluorouracil bleb needling performed 1 year or more posttrabeculectomy: a retrospective study. J Glaucoma. 2009;18(2):144-148.

19. Maestrini HA, Cronemberger S, Matoso HD, et al. Late needling of flat filtering blebs with adjunctive mitomycin C: Efficacy and safety for the corneal endothelium. Opthalmology. 2011;118:755-762.

20. Anand N, Khan A. Long-term outcomes of needle revision of trabeculectomy blebs with mitomycin $\mathrm{C}$ and 5-fluorouracil: a comparative safety and efficacy report. J Glaucoma. 2009;18(7):513-520.

21. Gracía García-Miguel T, Gutiérrez-Díaz E, Montero Rodríguez M, Sarmiento Torres B. Management of encapsulated blebs after glaucoma drainage device surgery. Arch Soc Esp Oftalmol. 2002;77(8):429-433. Spanish.

22. Jinza K, Saika S, Kin K, Ohnishi Y. Relationship between formation of a filtering bleb and an intrascleral aqueous drainage route after trabeculectomy; evaluation using ultrasound biomicroscopy. Ophthalmic Res. 2000;32:240-243.

23. Kaushik S, Tiwari A, Pandav SS, Ichhpujani P, Gupta A. Use of ultrasound biomicroscopy to predict long-term outcome of sub-Tenon needle revision of failed trabeculectomy blebs: a pilot study. Eur J Opthalmol. 2011;21(6):700-707.

24. [No authors listed]. The fluorouracil filtering surgery study group. Five-year follow-up of the Fluorouracil Filtering Surgery Study. Fluorouracil Filtering Surgery Study Group. Am J Ophthalmol. 1996;121: 349-366.

25. Chang $\mathrm{SH}$, Hou $\mathrm{CH}$. Needling revision with subconjunctival 5-fluourouracil in failing filtering blebs. Chang Gung Med J. 2002; 25(2):97-103.

26. Mazey BJ, Siegel MJ, Siegel LI, Dunn SP. Corneal endothelial toxic effect secondary to fluorouracil needle bleb revision. Arch Opthalmol. 1994;112:1411.

27. Pasternack JJ, Wand M, Shields MB, Abraham D. Needle revision of failed filtering blebs using 5-Fluorouracil and a combined ab-externo and ab-interno approach. J Glaucoma. 2005;14:47-51.
Clinical Ophthalmology

\section{Publish your work in this journal}

Clinical Ophthalmology is an international, peer-reviewed journal covering all subspecialties within ophthalmology. Key topics include: Optometry; Visual science; Pharmacology and drug therapy in eye diseases; Basic Sciences; Primary and Secondary eye care; Patient Safety and Quality of Care Improvements. This journal is indexed on Submit your manuscript here: http://www.dovepress.com/clinical-ophthalmology-journal

\section{Dovepress}

PubMed Central and CAS, and is the official journal of The Society of Clinical Ophthalmology (SCO). The manuscript management system is completely online and includes a very quick and fair peer-review system, which is all easy to use. Visit http://www.dovepress.com/ testimonials.php to read real quotes from published authors. 